\title{
COPIM
}

\section{COPIM Experimental Publishing Workshop - Part 1: Inhibitions Towards Experimental Book Publishing}

Samuel Moore, Janneke Adema

Published on: Oct 19, 2020

DOI: $10.21428 / 785 \mathrm{a} 6451.8265 \mathrm{afcb}$

License: Creative Commons Attribution 4.0 International License (CC-BY 4.0). 

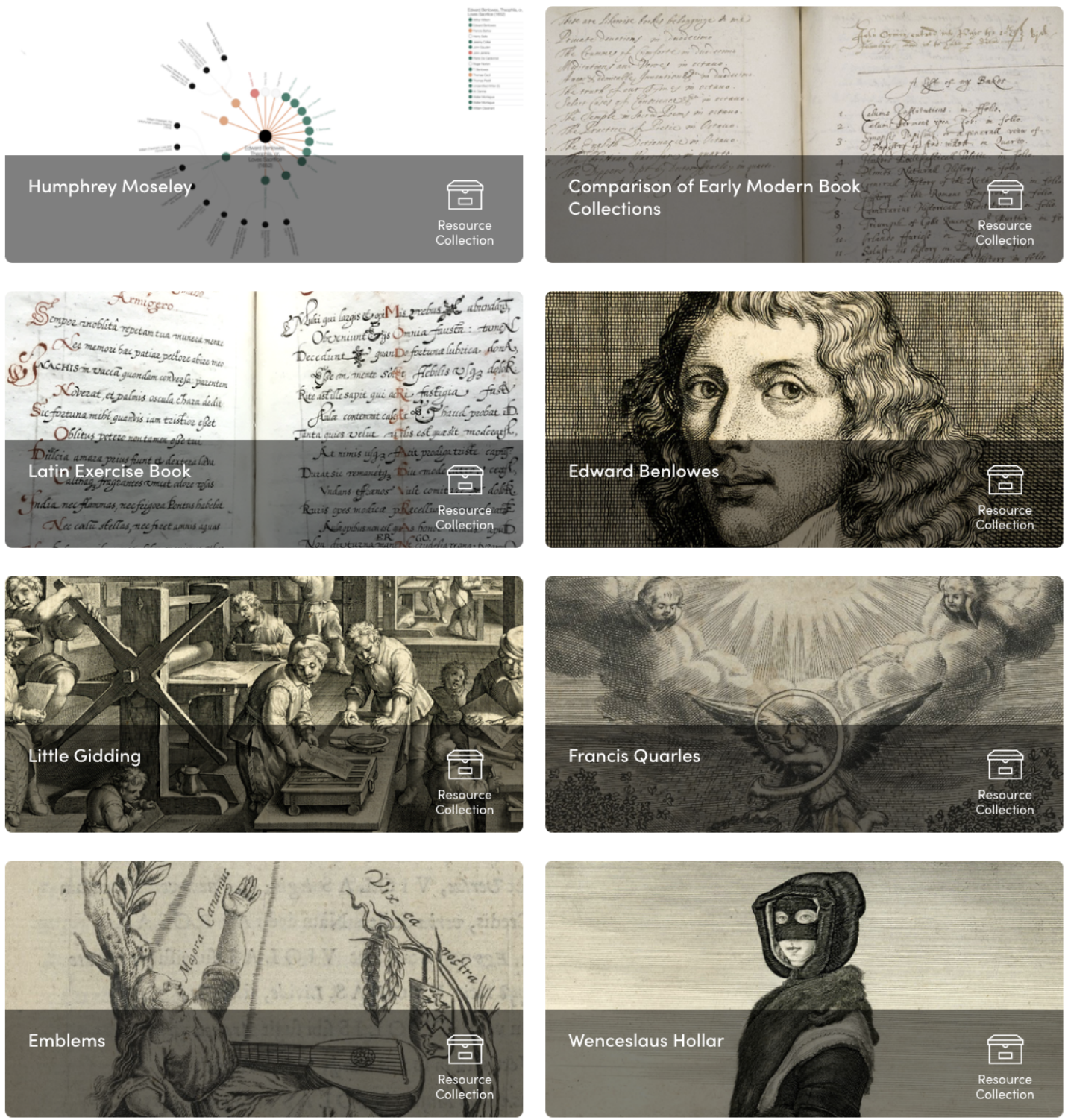

Resources from Whitney Trettien's Cut/Copy/Paste. Fragments of History Manifold Edition (University of Minnesota Press) https://manifold.umn.edu/projects/cut-copy_paste

Over the summer, the COPIM experimental publishing work package hosted an online workshop on Future Book Imaginaries: Mapping, Connecting, Developing, with leading practitioners, theorists and technologists (representing cutting-edge platforms and technologies), brought together by a shared interest in experimental forms of publishing and in reimagining the academic book. In the workshop 
we collaboratively explored how to better enable the production and publication of experimental books; and what is already out there to support this. Interested in facilitating knowledge exchange between publishers and technologists, we were seeking to understand the inhibitions towards experimental publishing by authors and publishers, along with ways to encourage exploration and uptake of experimentation. The workshop was organised by COPIM project members Janneke Adema, Gary Hall, Marcell Mars, Julien McHardy and Samuel Moore. Participants, listed with their projects, were: Cheryl Ball (Vega), Susan Doerr (University Minnesota Press/Manifold), Adam Hyde (Coko Foundation), Sarah Kember (Goldsmiths Press), Andreas Kirchner (Meson Press), Andrew Lockett (Westminster University Press), Tara McPherson (Scalar), Lara Speicher (UCL Press), Heather Staines (PubPub), Alessandra Tosi (Open Book Publishers), Whitney Trettien (thresholds) and Simon Worthington (Hybrid Publishing Group).

During the first part of the workshop we explored the main inhibitions with respect to the uptake of experimental publishing and reuse (i.e. from publishers and authors). The following is a summary of our discussions.

\section{Academic Reward Structures}

One of the biggest inhibitions towards adopting experimental practices - or any non-traditional practices - within academic publishing remains the (perceived or real) persistence of the requirement by hiring, tenure, and promotion committees for a certain kind of standard academic publication (e.g. a printed monograph or journal article), where digital scholarship and more experimental or multimodal forms of publishing are not always taken into equal consideration. Even though extensive resources have been developed over the years detailing how digital scholarship can be evaluated (Anderson and McPherson 2011; Risam 2014; Nyhan 2020)르, career concerns were still one of the most commonly cited inhibitions towards experimental publishing during the workshop, particularly the fact that experimental publishing is seen as risky and labour-intensive and not rewarded in the same way as more recognisable or traditional publications. Lara Speicher (UCL Press) noted that neither institutional management, nor their authors seem to consider experimentation important. Similarly, Andrew Lockett (Westminster University Press) highlighted how normally you would expect more experimentation from early-career researchers, however, in the present situation they tend to be rather risk-averse, even if they show interest in the value of experimentation itself.

Nevertheless, Whitney Trettien (thresholds) highlighted the fact that experimental publications are starting to be more valued and accepted within certain hiring and promotion contexts, for example within English and Media Studies in the US, and so this situation may be changing for the better. Yet even when academics do show an interest in experimentation, many of the workshop participants noted the persistence of traditional, print-based ideas of what a publication is. Conceptually, experimental publishing is somewhat difficult to grasp for many academics who have been 
conditioned to follow quite rigid publishing practices. As Cheryl Ball (Vega) noted, the more prestigious universities may be more inclined to reinforce tradition, even though they are in the best position to facilitate experimentation. This means that experimentation happens in places where it is either undervalued or unseen by the scholarly community at large. This devaluation leads to a state where, as Trettien added, experimental publishing becomes a "double-load" whereby it becomes extra work that people do on the side, once they have fulfilled their standard institutional publishing obligations.

\section{Lacking Technical Infrastructures and Skill Sets}

Furthermore, similar to what Adema and Stone observed as part of their landscape study of New University and scholar-led presses (2018) with respect to lacking technical know-how from publishers, many participants noted the new skill set that experimental publishing demands from authors and publishers, which may include learning new software, familiarising oneself with different forms of licensing, or even just being open to the idea of a different way of working. Adam Hyde (Coko) highlighted the increased emotional labour that comes from doing something collaboratively or experimentally, and fears around liberal licensing of scholarly work, while Tara McPherson (Scalar) argued for the need to "provide comfort" for authors who may be alienated by technical requirements or overwhelmed by the possibilities that experimentation offers. This is also related to the fact that experimental publishing occurs across the life cycle of a project, not just at the end, and so it tends to require projects to deeply consider publishing throughout the various stages of the research process.

Experimentation is also prevented by certain technical considerations beyond those that individual authors can address. Experimental publishing does not sit well with the idea of the lone humanist in the ivory tower; it often requires a team of editors, authors, and technologists to support an experimental publication. Collaborative publishing is not highly valued within humanities disciplines, while there are few incentives for publishers to restructure their work to encourage the kind of collaborative approach that experimental publishing necessitates.

\section{Preservation, licensing, and reuse}

Experimental publishing often requires a deep appreciation of archiving, preservation, and licensing, particularly as experimental publications are often processual. As noted, with commercial publishers less able or interested in providing such expertise for experimental publications, this expertise falls to institutions or is simply not addressed at all. As Cheryl Ball notes, this problem is exacerbated by the fleeting, performative nature of experimental publishing, which works against the possibility of building and supporting infrastructures for such efforts, especially when the technical possibilities and conceptual framings are continually shifting beneath our feet. The lack of routine approaches to preservation was one reason that Whitney Trettien was originally concerned about putting "a lot of time into something that would then disappear". For Ball, publishers should be taking the lead on 
preservation work, in collaboration with libraries and other organisations such as Portico, LOCKSS, and CLOCKSS. Some universities and presses are already taking the lead on ensuring more longevity and sustainability for digital scholarship and experimental forms of publishing, such as $\underline{\text { Stanford }}$ University Press's author guide on accessibility and preservation, and NYU Library's Mellon-funded work on preserving new forms of digital scholarship. Nonetheless, this work is ongoing and many of these issues remain without clear answers.

Related to preservation is the risk that many authors and publishers might feel around the open availability of long-form scholarship. For Sarah Kember (Goldsmiths Press), there is a feeling from authors that reuse of experimental monographs, particularly in accordance with Creative Commons licenses (especially CC BY), might undermine a projects "coherence" and undervalue the "investment" that is required to make it happen. This could be about a fear of commercialisation and wanting to prevent others from monetising your work, or it could be about wanting your project to remain a coherent whole and not have it removed from its original context.

\section{Conclusion}

Experimental publishing requires authors and publishers to reassess many of the assumptions around traditional publishing, but also to understand which values and practices to hold onto. Experimental publishing and digital scholarship can therefore jar with many of the assumptions and preconditions of contemporary higher education and publishing institutions. It is often labour intensive and requires a technical and conceptual skill set that many academics and publishers feel unequipped to deploy or explore. . As our participants noted, many of these issues will not be addressed without management taking a greater interest in experimentation, or without funders facilitating it. In the next blogpost we will be looking at opportunities to promote and support experimental forms of publishing: what kinds of tools are already out there and how can we use those both to further stimulate experimental publishing and the reuse of scholarship?

Header image: Screenshot of Whitney Trettien's Cut/Copy/Paste. Fragments of History Manifold Edition (University of Minnesota Press) https://manifold.umn.edu/projects/cut-copy_paste

\section{Footnotes}

1. Also see this great list maintained by the Group for Experimental Methods in Humanistic Research at Columbia University: https://github.com/dh$\underline{\text { notes/dhnotes/blob/master/pages/evaluating-digital-work.md }} \triangleq$ 